\title{
CATECHOLAMINE LEVELS IN THE BRAIN OF RATS EXPOSED BY INHALATION TO BENZALKONIUM CHLORIDE
}

\section{RADOSŁAW ŚWIERCZ, ZOFIA GRZELIŃSKA, SŁAWOMIR GRALEWICZ, and WOJCIECH WĄSOWICZ}

\author{
Nofer Institute of Occupational Medicine, Łódź, Poland \\ Department of Toxicology and Carcinogenesis
}

\begin{abstract}
Objectives: The aim of the study was to obtain quantitative data on the effect of inhalation exposure to benzalkonium chloride (BAC) on the concentration of catecholamines and their metabolites in selected brain structures. Additionally, concentration of corticosterone (CORT) in plasma was estimated. Material and Methods: Wistar rats were subjected to a single (6-hour) or repeated (3 days, $6 \mathrm{~h} /$ day) exposure to BAC aerosol at ca. $30 \mathrm{mg} / \mathrm{m}^{3}$. The Waters integrated analytical system of HPLC was used to determine the plasma corticosterone. Qualitative and quantitative determinations of catecholamines and their metabolites: 3,4-dihydroxyphenylacetic (DOPAC) and homovanillic (HVA) acids were performed with the use of the Waters integrity HPLC. Results: The determinations have shown that in the BAC-exposed rats the plasma CORT concentration was several times higher than in the control rats. A significant increase of the concentration of dopamine (DA) (striatum and diencephalon) and noradrenaline (NA) (hippocampus and cerebellum) and a significant reduction of adrenaline (A) level (cortex, hippocampus, striatum and mesencephaloon) was found to occur in the brain of rats exposed to BAC compared to control. In the animals exposed to BAC, the concentration of DOPAC, a DA metabolite, was significantly reduced, but the change occurred mainly in the striatum. This resulted in a significant decrease of the DOPAC/DA and HVA/DA metabolic ratio in this structure. Conclusion: It is assumed that the alterations in the concentration of catecholamines and their metabolites in the BAC-exposed rats were related to the unexpectedly strong and persistent activation of the hypothalamo-pituitary-adrenocortical (HPA) axis evidenced by the high plasma CORT concentration.
\end{abstract}

Key words:

Benzalkonium chloride, Rats, Inhalation exposure, Catecholamines, Brain, Corticosterone

\section{INTRODUCTION}

Benzalkonium chloride (BAC) belongs to the group of quaternary ammonium compounds. The bactericidal properties of BAC have been utilised since 1935 in the production of numerous drugs and cosmetic formulations. BAC has been also used as a disinfectant to clean rooms, glass vessels and surgical tools [1]. Various BAC-containing preparations may induce a number of adverse effects on the human body. Bearing in mind that BAC is widely used in different branches of the national economy, its toxic effect may cause health problems of significant importance to humans [2-6]. BAC has been included into human nasal spray formulations. Some reports suggest that BAC in nasal sprays may cause adverse effects, including reduced mucociliary transport, rhinitis medicamentosa and neutrophil dysfunction [3].

This work is an extension of our earlier work on rats under inhalation exposure to BAC aerosol in which, after $6 \mathrm{~h}$ inhalation, we noted a strong inflammatory and irritant activity on the lungs and stimulated dynamic patterns of interleukin 6 (IL-6) and immunoglobulin E (IgE) production and protein infiltration from blood vessels to bronchoalveolar lavage fluid (BALF) [7]. During those earlier tests, the animals were subjected to two strong stressors: head/nose immobilisation resulting from the selected method of exposure, and the irritant activity of the BAC

Received: April 14, 2009. Accepted: May 7, 2009.

Adderss reprint requests to R. Świercz, Department of Toxicology and Carcinogenesis, Nofer Institute of Occupational Medicine, św. Teresy 8, 91-348 Łódź, Poland (e-mail: radek@imp.lodz.pl). 
aerosol. Exposure to stressors results in a stress reaction. HPA axis activation, manifested by increased blood glucocorticoid level constitutes an essential element of that reaction. Glucocorticoids are important in the maintenance of functional and structural integrity of the brain. Therefore, increased blood glycocorticoid concentrations cause changes in the functional condition of the neurotransmission systems, and of the catecholaminergic systems in particular [8-10]. Data assessing BAC effects on central nervous system of experimental animals in inhalation exposure situations could not be located in the accessible literature. In this work we attempted a quantitative assessment of BAC effect on selected catecholamines and their metabolites in the brain of rats after inhalation exposure to $\mathrm{BAC}$ aerosol.

\section{MATERIALS AND METHODS}

\section{Chemicals}

Benzalkonium chloride (BAC) (CAS 8001-54-5) purity $\geq 95 \%$ was purchased from Fluka Chemie AG.

Ethylenediaminetetraacetic acid (EDTA), 1-octanesulfonic acid (Approx 98\%), Trizma ${ }^{\circledR}$ base (minimum 99.9\% titration), Trizma ${ }^{\circledR}$ hydrochloride, $( \pm)$-arterenol hydrochloride (NA), (-)-epinephrine (+)bitartrate salt (A), dopamine hydrochloride (DA), 3,4-dihydroxyphenylacetic acid (DOPAC), 4-hydroxy-3methoxy-phenylacetic acid (HVA), corticosterone, betamethasone and aluminium oxide (type WN-3 neutral) were purchased from SIGMA. Acetic acid (99-100\%), perchloric acid (70-72\%), phosphoric acid (85\%), potassium phosphate (monobasic ultrapure), methanol, dichloromethane, diethyl ether and sodium chloride (ultrapure) were purchased from J.T. BAKER. 3,4-dihydroxybenzylamine hydrobromide (98\%) was purchased from ALDRICH. Activated charcoal Norit was purchased from Fluka.

\section{Animals and inhalation exposure}

Female Wistar rats, aged 2 to 3 months, that were obtained from the breeding farm of the Nofer Institute of Occupational Medicine, Łódź, Poland, were used in the experiment. At each stage of the study, groups of five animals were investigated: the exposed animals as the study group and unexposed ones as the controls. During the testing, both groups were kept in exposure chambers but the control rats inhaled atmospheric air; other environmental conditions: temperature, humidity, and food and water intake were the same for the two groups. The chemical to be tested was injected into exposure chamber with a dynamic air flow to ensure 15 air changes per hour, so that the rat's head/nose would be directly exposed to BAC as an aqueous aerosol. BAC concentration in the chamber was monitored by HPLC. Rats were exposed to BAC aerosol at the target concentration of $30 \mathrm{mg} / \mathrm{m}^{3}$ for $6 \mathrm{~h}$ or 3 days (6 h/day) [7].

\section{Biological material collection}

The brain was collected from the exposed and control animals $18 \mathrm{~h}$ after termination of the last exposure. The sacrifice took place between 8 and 9 a.m. The brains were removed from skulls as quickly as possible, chilled in ice-cold sodium chloride $(0.9 \%)$ for approximately $5 \mathrm{~min}$ and sectioned on ice into the following parts: hippocampus, striatum (n. caudatus and putamen), occipito-temporal cortex (with underlying white matter), diencephalon, mesencephalon and cerebellum. Corresponding tissue samples from right and left hemisphere were pooled, weighed (with $0.001 \mathrm{~g}$ accuracy), supplemented with five parts of ice-cold water (HPLC) and homogenized for $30 \mathrm{~s}$. Homogenate samples (450 $\mu \mathrm{l})$ were supplemented with $50 \mu \mathrm{l}$ of $4 \mathrm{M} \mathrm{HClO}_{4}$ and centrifuged. The supernatants were filtered and stored at $-20^{\circ} \mathrm{C}$ until analysis.

Blood samples were collected into Vacutainers containing an anticoagulant $\left(\mathrm{K}_{2} \mathrm{EDTA}, 10.8 \mathrm{mg}\right)$. After centrifuging $(10 \mathrm{~min}, 1780 \times \mathrm{g})$, the serum was transferred to Eppendorf vessels and stored at $-20^{\circ} \mathrm{C}$ until analysis.

\section{Catecholamine, serotonin, metabolite}

\section{and corticosterone assay}

The brain concentrations of noradrenaline (NA), adrenaline (A), dopamine (DA), 3,4-dihydroxyphenylacetic acid (DOPAC) and homovanillic acid (HVA) were determined by HPLC. DOPAC and HVA were assayed 
directly in the supernatant. Prior to chromatographic analysis, NA, A and DA were purified by absorption on aluminium oxide [11].

The content of corticosterone in plasma was estimated by high performance liquid chromatography (HPLC) using betamethasone as an internal standard [12].

\section{Statistical analysis}

Differences were assessed using the Kruskall-Wallis test in Dunn's modification [13]. The trend analysis was performed with the use of Jonckheere's test [14]. Differences were regarded as significant when the probability of the null hypothesis was $<0.05$.

\section{RESULTS}

All animals exposed to BAC aerosol at ca. $30 \mathrm{mg} / \mathrm{m}^{3}$ survived the inhalation exposure. Table 1 shows true BAC aerosol concentration in exposure chamber atmosphere, mean weight of animal bodies and brains, and corticosterone levels in blood plasma of control and BAC aerosol-exposed rats. Values for the control group given in Tables 1, 2 and 3 represent combined results obtained for the control groups in the 6-h and 3-day inhalation exposure experiments; the combination has been feasible because there were no statistically significant differences in the respective 6-h and 3-day results.

The statistical analysis did not show differences in body or brain weight between the exposed and control rats.
Blood plasma corticosterone concentrations in the groups of the exposed animals were significantly higher than in the control. Corticosterone increase in the groups of the exposed animals was related to the time of BAC exposure $\left(\mathrm{p}_{\mathrm{J}}<0.001\right)$. In the 6-h BAC-exposed animals, mean corticosterone concentration was three times higher, while in 3-day BAC-exposed ones it was over four times higher relative to control.

Table 2 shows absolute values of concentrations of the studied compounds in the selected brain structures of the control animals. The respective results for the exposed groups are given in terms of control group per cent values.

The statistical analysis revealed that the majority of the quantitative changes occurring in the studied structures of the exposed rat brains were changes of A. Significantly reduced concentration of A was recorded in four (cortex, hippocampus, striatum, mesencephaloon) out of the six studied brain structures. The observed trend in the concentration of A was more pronounced with longer exposure time, as reflected by the results of trend analysis (Table 2). Concentrations of DA and NA in BAC-exposed animals were significantly higher only in some of the brain structures (Table 2). In the two BAC-exposed groups, increased DA concentration was detected in mesencephalon only. NA concentration was significantly higher in hippocampus and cerebellum of the 3-day BAC-exposed rats. The statistical analysis of the concentrations of two dopamine metabolites showed significantly lower DOPAC

Table 1. Air concentration of BAC aerosol (mean $\pm \mathrm{SD}$ ) in inhalation chambers and brain weight (means $\pm \mathrm{SD}$ ), body weight and levels of corticosterone in the plasma of experimental rats

\begin{tabular}{|c|c|c|c|c|c|}
\hline $\begin{array}{c}\text { Treatment } \\
(\mathrm{n}=\text { animals per } \\
\text { treatment })\end{array}$ & $\begin{array}{c}\text { BAC aerosol } \\
\text { concentration in } \\
\text { inhaled air } \\
\left(\mathrm{mg} / \mathrm{m}^{3}\right)\end{array}$ & $\begin{array}{l}\text { Body weight } \\
\text { (g) }\end{array}$ & $\begin{array}{l}\text { Brain weight } \\
\text { (g) }\end{array}$ & $\begin{array}{l}\text { Relative brain weight } \\
\quad(\mathrm{g} / 100 \mathrm{~g} \text { b.w.) }\end{array}$ & $\begin{array}{c}\text { Corticosterone } \\
\text { concentrations } \\
\text { in the plasma } \\
(\mathrm{ng} / \mathrm{ml})\end{array}$ \\
\hline Control $(n=10)$ & 0 & $189.5 \pm 6.4$ & $1.75 \pm 0.08$ & $0.92 \pm 0.06$ & $194.9 \pm 76.7$ \\
\hline BAC $6 \mathrm{~h}(\mathrm{n}=5)$ & $28.0 \pm 6.0$ & $176.0 \pm 5.5$ & $1.75 \pm 0.09$ & $0.99 \pm 0.05$ & $564.4 \pm 195.9^{*}$ \\
\hline $\begin{array}{l}\text { BAC } 3 \text { days, } \\
6 \text { h/day }(\mathrm{n}=5)\end{array}$ & $30.5 \pm 4.2$ & $180.0 \pm 10.0$ & $1.62 \pm 0.08$ & $0.90 \pm 0.07$ & $874.2 \pm 396.3^{* *}$ \\
\hline
\end{tabular}

Results expressed as mean $\pm \mathrm{SD}$.

*, ** Significantly different from control at $\mathrm{p} \leq 0.05$ and $\mathrm{p} \leq 0.01$, respectively. 
Table 2. Brain contents of dopamine (DA), noradrenaline (NA), adrenaline (A), 3,4-dihydroxyphenylacetic acid (DOPAC) and homovanillic acid (HVA) in rats exposed for $6 \mathrm{~h}$ or 3 days $\left(6 \mathrm{~h} /\right.$ day) to $30 \mathrm{mg} \mathrm{BAC} / \mathrm{m}^{3}$

\begin{tabular}{|c|c|c|c|c|c|}
\hline \multirow[b]{2}{*}{ Chemical } & \multirow[b]{2}{*}{ Brain region } & \multicolumn{3}{|c|}{ Exposure group } & \multirow{2}{*}{$\begin{array}{l}\text {-Jonckheere's trend tes } \\
\qquad\left(\mathrm{p}_{\mathrm{J}}\right)\end{array}$} \\
\hline & & $\begin{array}{l}\text { Control } \\
\text { (nmol/g) }\end{array}$ & $\begin{array}{c}\text { BAC } 6 \mathrm{~h} \\
(\% \text { Control })\end{array}$ & $\begin{array}{l}\text { BAC } 3 \text { days } \\
\text { (\% Control) }\end{array}$ & \\
\hline \multirow[t]{6}{*}{ DA } & Cortex & $0.37(0.22)$ & $100.3(47.9)$ & $143.6(66.7)$ & $\mathrm{ns}$ \\
\hline & Hippocampus & $0.77(0.62)$ & $83.3(26.8)$ & $104.4(40.2)$ & $\mathrm{ns}$ \\
\hline & Striatum & $11.30(4.94)$ & $177.1(67.9)$ & $195.2(118.4)$ & 0.02 \\
\hline & Diencephalon & $0.91(0.30)$ & $247.6(145.0)^{*}$ & $164.6(33.2)^{*}$ & 0.01 \\
\hline & Mesencephalon & $0.60(0.38)$ & $127.2(47.7)$ & $118.2(17.1)$ & $\mathrm{ns}$ \\
\hline & Cerebellum & $0.29(0.08)$ & $145.5(40.9)$ & $129.6(56.2)$ & $\mathrm{ns}$ \\
\hline \multirow[t]{6}{*}{ NA } & Cortex & $6.83(4.05)$ & $66.4(28.4)$ & $99.0(52.1)$ & $\mathrm{ns}$ \\
\hline & Hippocampus & $6.04(3.88)$ & $84.9(24.9)$ & $226.5(127.6)^{*}$ & 0.05 \\
\hline & Striatum & $7.93(4.16)$ & $61.6(20.8)$ & $135.6(79.4)$ & $\mathrm{ns}$ \\
\hline & Diencephalon & $11.88(3.65)$ & $103.7(33.3)$ & $96.3(18.8)$ & $\mathrm{ns}$ \\
\hline & Mesencephalon & $7.46(1.69)$ & $91.1(17.8)$ & $127.1(50.3)$ & $\mathrm{ns}$ \\
\hline & Cerebellum & $3.00(1.45)$ & $175.5(44.2)$ & $493.8(312.9)^{* *}$ & 0.01 \\
\hline \multirow[t]{6}{*}{ A } & Cortex & $0.63(0.25)$ & $81.5(36.4)$ & $62.6(18.6)^{*}$ & 0.05 \\
\hline & Hippocampus & $0.49(0.27)$ & $72.4(21.6)$ & $45.0(10.9)^{* *}$ & 0.01 \\
\hline & Striatum & $0.71(0.23)$ & $86.6(39.9)$ & $45.9(22.8)^{* *}$ & 0.02 \\
\hline & Diencephalon & $0.40(0.19)$ & $104.4(18.2)$ & $65.5(18.9)$ & $\mathrm{ns}$ \\
\hline & Mesencephalon & $0.47(0.17)$ & $49.5(9.9)^{* *}$ & $46.7(19.9)^{* *}$ & 0.001 \\
\hline & Cerebellum & $0.38(0.05)$ & $73.3(18.6)$ & $139.9(69.6)$ & ns \\
\hline \multirow[t]{6}{*}{ DOPAC } & Cortex & $4.50(2.78)$ & $52.3(12.3)$ & $105.4(43.9)$ & $\mathrm{ns}$ \\
\hline & Hippocampus & $6.80(2.88)$ & $71.8(12.1)$ & $54.1(23.4)^{*}$ & $\mathrm{~ns}$ \\
\hline & Striatum & $128.49(39.00)$ & $58.4(15.6)^{*}$ & $53.1(30.1)^{* *}$ & 0.001 \\
\hline & Diencephalon & $11.13(5.66)$ & $122.6(48.7)$ & $74.9(22.0)$ & $\mathrm{ns}$ \\
\hline & Mesencephalon & $4.14(0.95)$ & $123.9(51.6)$ & $95.6(22.8)$ & $\mathrm{ns}$ \\
\hline & Cerebellum & $1.22(0.29)$ & $100.2(28.4)$ & $89.4(15.7)$ & $\mathrm{ns}$ \\
\hline \multirow[t]{6}{*}{ HVA } & Cortex & $1.80(0.87)$ & $66.9(16.1)$ & $116.4(57.5)$ & $\mathrm{ns}$ \\
\hline & Hippocampus & $1.36(0.74)$ & $82.2(25.5)$ & $62.9(25.5)$ & $\mathrm{ns}$ \\
\hline & Striatum & $24.35(6.61)$ & $85.5(23.9)$ & $101.8(55.2)$ & $\mathrm{ns}$ \\
\hline & Diencephalon & $1.96(0.44)$ & $135.0(56.4)$ & $140.4(31.7)^{*}$ & 0.02 \\
\hline & Mesencephalon & $1.17(0.43)$ & $102.2(21.3)$ & $102.5(34.8)$ & $\mathrm{ns}$ \\
\hline & Cerebellum & $0.33(0.11)$ & $84.7(23.6)$ & $69.4(20.7)$ & 0.05 \\
\hline
\end{tabular}

Results expressed as mean $\pm \mathrm{SD}$.

$*$, ** Significantly different from control at $\mathrm{p} \leq 0.05$ and $\mathrm{p} \leq 0.01$, respectively.

ns - not significant.

concentration in the hippocampus of the 3-day BACexposed rats and in the striatum of both BAC-exposed groups. Our analysis of HVA concentration in the BACexposed animals showed elevated concentration in mesencephalon and lower concentration of the metabolite in the cerebellum.

Table 3 shows DOPAC/DA and HVA/DA ratios. The DOPAC/DA ratio was significantly lower in striatum 
Table 3. DOPAC/DA and HVA/DA ratios in brain regions of control rats and rats exposed for $6 \mathrm{~h}$ or 3 days $\left(6 \mathrm{~h} /\right.$ day) to $30 \mathrm{mg} \mathrm{BAC} / \mathrm{m}^{3}$

\begin{tabular}{clcccc}
\hline \multirow{2}{*}{ Ratio } & \multicolumn{1}{c}{ Brain region } & \multicolumn{3}{c}{ Exposure group } & $\begin{array}{c}\text { Jonckheere's trend } \\
\text { test } \\
\left(\geq \mathrm{p}_{\mathrm{J}} \text { ) }\right.\end{array}$ \\
\cline { 3 - 5 } & & Control & BAC 6 h & BAC 3 days & $\mathrm{ns}$ \\
\hline DOPC/DA & Cortex & $13.98(7.86)$ & $8.01(5.00)$ & $9.67(3.49)$ & $\mathrm{ns}$ \\
& Hippocampus & $19.92(18.38)$ & $8.49(3.98)$ & $4.88(1.64)$ & 0.001 \\
& Striatum & $14.33(8.45)$ & $4.53(1.59)^{*}$ & $3.76(2.28)^{* *}$ & 0.01 \\
& Diencephalon & $13.77(8.48)$ & $6.72(1.59)^{*}$ & $5.61(1.42)^{* *}$ & $\mathrm{~ns}$ \\
& Mesencephalon & $10.39(7.03)$ & $7.59(4.07)$ & $5.55(0.78)$ & $\mathrm{ns}$ \\
& Cerebellum & $4.52(1.96)$ & $2.95(0.63)$ & $3.29(1.34)$ & $\mathrm{ns}$ \\
& Cortex & $5.60(2.43)$ & $3.92(2.27)$ & $4.04(0.92)$ & $\mathrm{ns}$ \\
& Hippocampus & $4.30(4.31)$ & $1.90(0.96)$ & $1.19(0.55)$ & 0.01 \\
& Striatum & $2.64(1.72)$ & $1.01(0.32)^{* *}$ & $1.13(0.43)^{*}$ & $\mathrm{~ns}$ \\
& Diencephalon & $2.39(0.98)$ & $1.29(0.35)^{* *}$ & $1.85(0.32)$ & $\mathrm{ns}$ \\
& Mesencephalon & $3.23(2.71)$ & $1.74(0.67)$ & $1.66(0.48)$ & 0.001 \\
\hline
\end{tabular}

Results expressed as mean \pm SD.

$*, * *$ Significantly different from control at $\mathrm{p} \leq 0.05$ and $\mathrm{p} \leq 0.01$, respectively. ns - not significant.

and mesencephalon of both BAC-exposed groups relative to control. Lower HVA/DA ratios were noted in the same brain structures and in the cerebellum of exposed animals.

\section{DISCUSSION AND CONCLUSIONS}

High blood corticosterone concentrations were noted in the BAC-exposed animals (Table 1). This is indicative of a strong, prolonged (18 h since exposure termination) activation of the hypothalamo-pituitary-adrenocortical (HPA) axis in BAC-exposed animals. It is generally recognised that HPA axis activation may cause a number of not necessarily advantageous changes in the animal and human nervous systems [15]. It has been proven that corticosterone elevation induces dendritic atrophy in hippocampal neurons, which is paralleled by cognitive deficits in spatial learning and memory [16]. It is likely that inhalation exposure to BAC may produce adverse effects within the nervous system of the animals exposed to high BAC aerosol concentrations, attributable to the observed high blood corticosterone concentrations of BAC-exposed animals.
It is also recognised that HPA axis activation triggers functional state changes in the neurotransmission systems, and the catecholaminergic systems in particular, in the central nervous system $[10,17,18]$. Strong stress causes a reduction in adrenaline concentration and affects dopamine (DA) metabolism in different brain regions, leading to the formation of one of its principal acidic metabolites, dihydroxyphenylacetic acid (DOPAC) $[19,20]$. On the other hand, elevated glucocorticoid concentration in the adrenal medulla enhances the induction of enzymes that control the synthesis of A from NA [21].

Table 4 shows changes in the concentrations of DA, NA, A, DOPAC, HVA, and DOPAC/DA and HVA/ DA ratios that occur in different brain structures of 6-h or 3-day BAC-exposed rats compared to control.

In the analysed brain structures of BAC-exposed animals, DA and NA concentrations grew in a different way in different areas of rat brain compared to controls. Adrenaline concentrations, on the other hand, decreased. Growing DA and/or NA concentrations in the brain of animals subjected to stress is a reaction which has been observed by many authors $[9,10,22]$. In stressed animals, like in our study, a significant reduction of the DOPAC/DA and 
Table 4. Changes in dopamine (DA), noradrenaline (NA), adrenaline (A), 3,4-dihydroxyphenylacetic acid (DOPAC), homovanillic acid (HVA) levels and DOPAC/DA, HVA/DA ratios in rats exposed for $6 \mathrm{~h}$ or 3 days $\left(6 \mathrm{~h} /\right.$ day) to $30 \mathrm{mg} \mathrm{BAC} / \mathrm{m}^{3}$

\begin{tabular}{|c|c|c|c|c|c|c|c|c|c|c|c|c|c|c|}
\hline \multirow{4}{*}{ Brain region } & \multicolumn{14}{|c|}{ Chemical or ratio } \\
\hline & \multicolumn{2}{|c|}{ DA } & \multicolumn{2}{|c|}{ NA } & \multicolumn{2}{|c|}{$\mathrm{A}$} & \multicolumn{2}{|c|}{ DOPAC } & \multicolumn{2}{|c|}{ HVA } & \multicolumn{2}{|c|}{$\begin{array}{c}\text { DOPAC } \\
/ \mathrm{DA}\end{array}$} & \multicolumn{2}{|c|}{ HVA/DA } \\
\hline & \multicolumn{14}{|c|}{ Exposure group } \\
\hline & $6 \mathrm{~h}$ & $3 \mathrm{~d}$ & $6 \mathrm{~h}$ & $3 \mathrm{~d}$ & $6 \mathrm{~h}$ & $3 \mathrm{~d}$ & $6 \mathrm{~h}$ & $3 \mathrm{~d}$ & $6 \mathrm{~h}$ & $3 \mathrm{~d}$ & $6 \mathrm{~h}$ & $3 \mathrm{~d}$ & $6 \mathrm{~h}$ & $3 \mathrm{~d}$ \\
\hline Cortex & & + & & & - & -- & & & & & & & & \\
\hline Hippocampus & & & & ++ & - & -- & & -- & & & & & & \\
\hline Striatum & + & + & & & - & -- & -- & -- & & & -- & -- & -- & -- \\
\hline Diencephalon & ++ & ++ & & & & & & & + & ++ & -- & -- & -- & - \\
\hline Mesencephalon & & & & & -- & -- & & & & & & & & \\
\hline Cerebellum & & & + & ++ & & & & & - & - & & & -- & -- \\
\hline
\end{tabular}

+ Insignificant increase; + + significant increase; - insignificant decrease; -- significant decrease.

HVA/DA ratios has been observed [10]. Missing data on BAC's ability to penetrate through the blood/brain barrier causes that it is not possible to positively assess the direct BAC effect on DA-metabolising enzymes in the brain. BAC effect through its strong irritating activity with simultaneous inflammatory process in the lungs of the exposed animals seems to be more likely [7]. However, it is also likely that, instead of the whole BAC molecule, at least some part of it may pass through the blood/ brain barrier to inhibit DA metabolism in the brain. Pargyline is known to affect DA enzymatic metabolism involving inhibition of monoamine oxidase (MAO) that participates in the metabolism of catecholamines. Pargyline and BAC belong to the same group of chemicals, the aromatic amines [23].

Tosum up, changesin the concentrations of catecholamines in the brain of rats exposed by inhalation to BAC aerosol suggest that inhalation exposure to BAC may significantly affect the functional condition of the catecholaminergic systems, and of the dopaminergic system in particular. The intensity of the detected changes is exposure timerelated. Striatum and diencephalon were brain regions in which the changes were most evident. High CORT concentrations in blood plasma of the exposed animals support the conjecture that the observed changes in catecholamine concentrations were attributable to a strong and prolonged activation of the HPA axis.

\section{RFFERENCES}

1. Graf P. Adverse effects of benzalkonium chloride on the nasal mucosa: allergic rhinitis and rhinitis medicamentosa. Clin Ther 1999;21(10):1749-55.

2. Berkel M, Wolff FA. Survival after acute benzalkonium chloride poisoning. Hum Toxicol 1988;7:191-3.

3. Bernstein IL. Is the use of benzalkonium chloride as a preservative for nasal formulations a safety concern? A cautionary note based on compromised mucociliary transport. J Allergy Clin Immunol 2000;105:39-44.

4. Cox NH. Allergy to benzalkonium chloride simulating dermatomyositis. Contact Dermatitis 1994;31:50.

5. Hitosugi M, Maruyama K, Takatsu A. A case of fatal benzalkonium chloride poisoning. Int J Legal Med 1998;111:265-6.

6. Riechelmann H, Deutschle T, Stuhlmiller A, Gronau S, Bürner H. Nasal toxicity of benzalkonium chloride. Am J Rhinol 2004;18(5):291-9.

7. Świercz R, Hałatek T, Wąsowicz W, Kur B, Grzelińska Z, Majcherek W. Pulmonary irritation after inhalation exposure to benzalkonium chloride in rats. Int J Occup Med Environ Health 2008;21(2):157-63. DOI 102478/v1001-008-00201.

8. Marinelli M, Piazza PV. Interaction between glucocorticoid hormones, stress and psychostimulant drugs. Eur J Neurosci 2002;16:387-94.

9. Sirivelu MP, MohanKumar SMJ, Wagner JG, Harkema JR, MohanKumar PS. Activation of the stress axis and neurochemical alterations in specific brain areas by concentrated ambient 
particle exposure with concomitant allergic airway disease. Environ Health Perspect 2006;114:870-4.

10. Torres ILS, Gamaro GD, Vasconcells AP, Silveira R, Dalmaz C. Effects of chronic restraint stress on feeding behavior and on monoamine levels in different brain structures in rats. Neurochem Res 2002;27(6)519-25.

11. Świercz R, Grzelińska Z, Majcherek W, Wiaderna P, Lutz P, Sitarek K, et al. Brain catecholamine concentrations in adult rats exposed perinatally to methylmercury and/or PCB 153. Pol J Environ Studies 2008;17(4)587-96.

12. Ling S, Jamali F. Effect of cannulation surgery and restraint stress on the plasma corticosterone concentration in the rat: application of an improved corticosterone hplc assay. J Pharm Pharmaceuti Sci 2003;6(2):246-51.

13. Dunn OJ. Multiple comparison using rank sums. Technometrics 1964;6:241-52.

14. Jonckheere AR. A distribution-free $k$-sample test against ordered alternatives. Biometrika 1954;41:135-45.

15. Reagan LP, Grillo CA, Piroli GG. The As and Ds of stress: Metabolic, morphological and behavioral consequences. Eur J Pharmacol 2008;585:64-75.

16. Raber J. Detrimental effects of chronic hypothalamic-pituitaryadrenal axis activation. Mol Neurobiol 1998;18(1):1-22.
17. Makino S, Smith MA, Gold PW. Regulatory role of glucocorticoids and glucocorticoid receptor $m R N A$ levels on tyrosine hydroxylase gene expression in the locus coeruleus during repeated immobilization stress. Brain Res 2002;943:216-223.

18. Sabban EL, Kvetnansky R. Stress-triggered activation of gene expression in catecholaminergic systems: dynamics of transcriptional events. Trends Neurosci 2001;24(2):91-8.

19. Antelman SM, Caggiula AR, Kocan D, Knopf S, Meyer D, Edwards DJ, et al. One experience with 'lower' or 'higher' intensity stressors, respectively enhances or diminishes responsiveness to haloperidol weeks later: implications for understanding drug variability. Brain Res 1991;566:276-83.

20. Weiss SJ. Neurobiological alterations associated with traumatic stress. Perspect Psychiatr Care 2007;43(3):114-22.

21. Zimecki M, Artym J. The effect of psychic stress on the immune response. Postępy Hig Med Dosw 2004;58:166-75 [in Polish].

22. Stenfors C, Bjellerup P, Mathe AA, Theodorsson E. Concurrent analysis of neuropeptides and biogenic amines in brain tissue of rats treated with electroconvulsive stimuli. Brain Res 1995;698:39-45.

23. Fuentes JA, Ordaz A, Neff NH. Central mediation of the antihypertensive effect of pargyline in spontaneously hypertensive rats. Eur J Pharmacol 1979;57(1):21-7. 